\title{
ENERgy StORAgE SYSTEMS
}

\section{(Sistemas de ARMAZenamento de Energia)}

\section{Sistemas de Armazenamento de Energia}

O armazenamento de energia pode ser efetuado sobre cinco categorias, designadamente, elétrica, eletromecânica, mecânica, térmica e química. Contudo, o assunto aqui debatido é sobre meios de armazenamento de energia elétrica, sendo que o armazenamento de eletricidade é usualmente efetuado recorrendo a outros géneros de energia, tais como, química, mecânica, térmica ou, até, em energia potencial. [1].

Há nos dias de hoje uma crescente preocupação na forma como é gerido o setor elétrico, uma vez que este implica um elevado impacto ambiental. Neste sentido tem havido algumas alterações, nomeadamente, no que diz respeito à produção de energia elétrica. A utilização de energias renováveis estão cada vez mais presentes na produção de eletricidade (Figura 1), pois permitem diminuir de forma indireta a utilização dos combustíveis fósseis, sendo esta a principal vantagem face às centrais de produção convencionais.
Em contrapartida, as energias renováveis conduzem a problemas de imprevisibilidade, devido ao facto de este tipo de produção estar dependente das condições climáticas, época do ano e da hora do dia, por exemplo, a geração de energia eólica está condicionada pela presença ou não do vento com determinadas caraterísticas [1] [2].

No setor elétrico é muito importante manter o equilíbrio entre a produção e o consumo, como tal, os sistemas de armazenamento de energia elétrica, designado por energy storage systems (ESS) na literatura anglo-saxónica, podem ser usados para contribuir para esse equilíbrio. Como tal, estes sistemas permitem atenuar o problema da intermitência de produção, que é uma lacuna das energias renováveis [1] [3].

Deste modo, o uso dos ESS's permitem uma maior racionalidade tanto nos recursos energéticos como a nível económico, pois a produção de energia elétrica traduzem custos avultados. Assim, reforça-se a necessidade de incorporar os ESS's na rede elétrica de energia.

Evolução do peso da electricidade de origem renovável em Portugal entre 1999 e 2012

(com correcção de hidraulicidade)

APREN

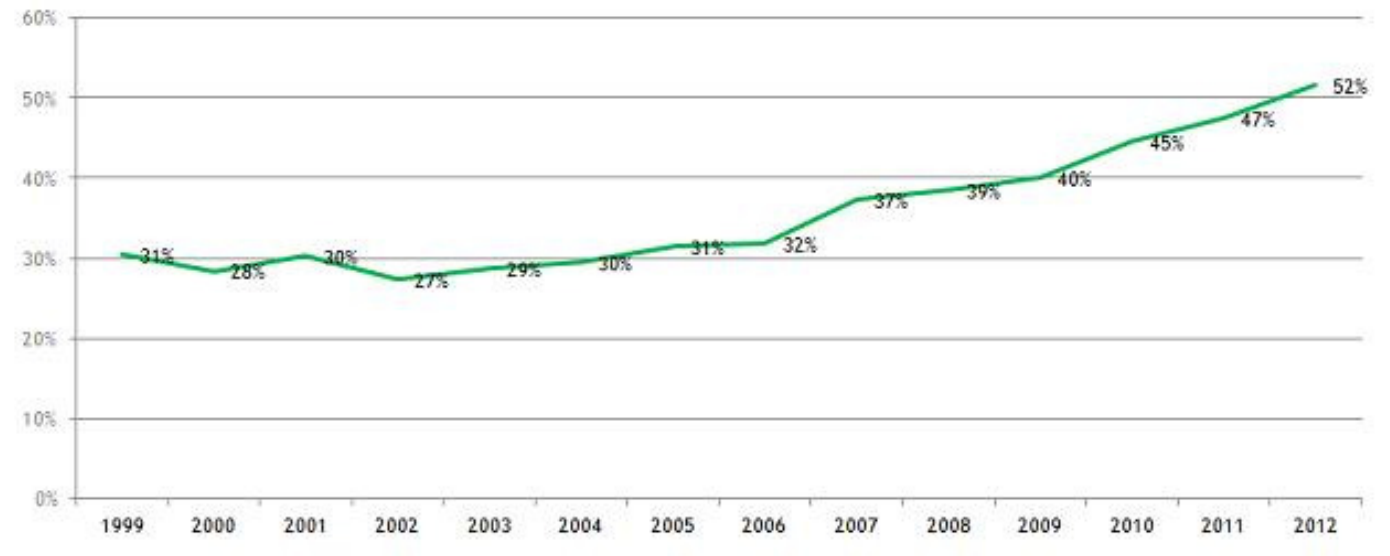

Figura 1 - Evolução do peso da eletricidade de origem renovável em Portugal entre 1999 e 2012 [2] 
Os ESS's, quando integrados num sistema elétrico, são unidades cuja utilização é destinada a duas funções, ou seja, podem funcionar como "carga", caso estejam a armazenar energia elétrica, ou podem funcionar como "gerador" nos períodos em que estes estão a descarregar energia elétrica para a rede.

Essencialmente, um ESS armazena energia quando há excesso de produção em relação à procura num determinado momento, permitindo assim, diminuir o desperdício de energia elétrica. Com a possibilidade de reserva de energia consegue-se diminuir o dispêndio de recursos naturais na geração da mesma, nomeadamente, redução de combustíveis fósseis [2] [3].

Este artigo pretende salientar a importância dos ESS's em aproveitar a energia produzida em excesso, e assim ter a possibilidade de a utilizar numa fase posterior de maior necessidade energética ou, caso seja mais vantajoso, vendê-la.

\section{Características dos ESS's}

Segundo [4], um ESS é constituído por quatro principais componentes como pode ser observado na Figura 2.

Verifica-se, portanto, que os quatro componentes correspondem aos sistemas de carregamento e de descarregamento, ao processo de monitorização e controlo, e claro, aos próprios mecanismos de armazenamento.
Posteriormente, o ESS deve-se encontrar interligado com a rede elétrica de modo a ocorrer as devidas trocas de energia.

O elemento designado por "Mecanismo de Armazenamento" corresponde ao próprio meio de armazenamento, e como tal, estabelece os limites da capacidade de armazenar energia do sistema. Como já foi referido anteriormente, existem diversas tecnologias de armazenamento, que posteriormente serão descritas no ponto 4 .

Outro elemento presente no sistema de armazenamento é o "Sistema de Carregamento", que tem a função de converter a energia proveniente do sistema num outro tipo de energia (caso necessário), de modo a que esta possa ser armazenada. Para além deste equipamento, no ESS está também presente o "Sistema de Descarregamento", com funções contrárias às do anterior, ou seja, este equipamento permite pegar na energia armazenada e convertê-la de forma a poder ser utilizada na rede.

Por exemplo, na Figura 3 pode-se ver um processo de armazenagem de energia térmica, que quando necessária pode ser transformada em energia elétrica.

Por último, há o "Sistema de Controlo", que por sua vez, consiste em dois subsistemas. O primeiro corresponde à fase de monitorizar e controlar o equipamento em si e o segundo diz respeito ao sistema de controlo do sistema de armazenamento.

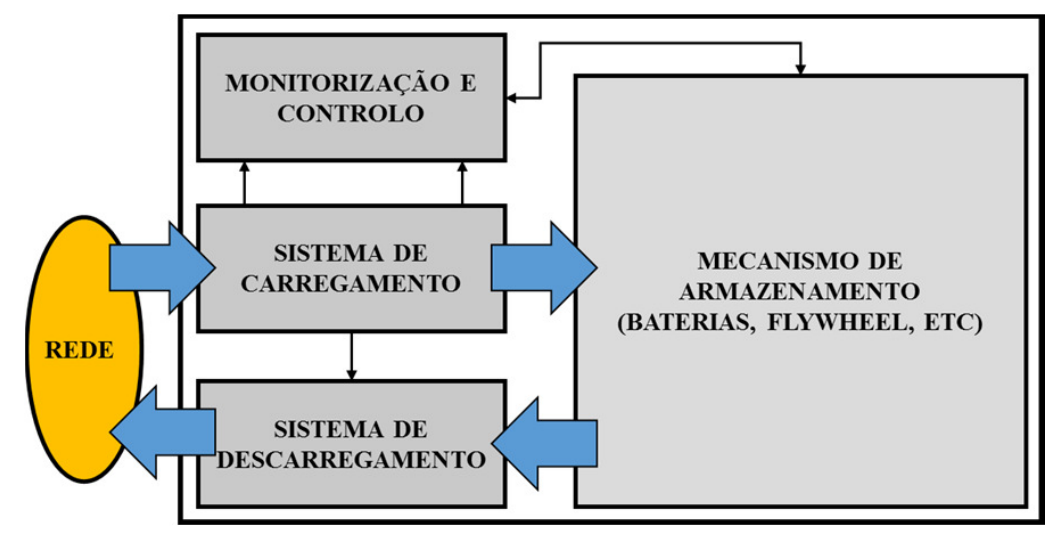

Figura 2 - Principio básico do funcionamento de um ESS - adaptado de [4] 


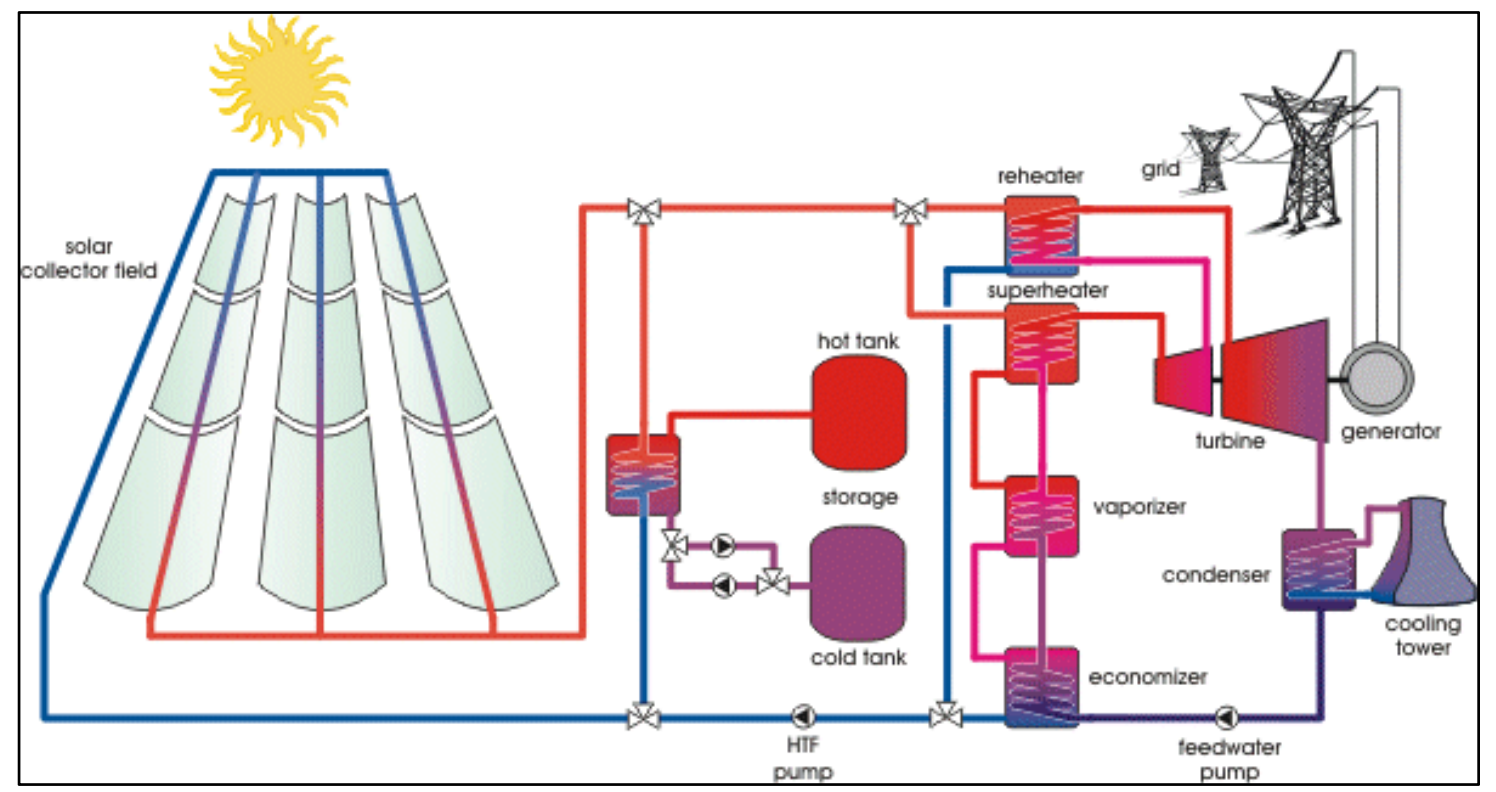

Figura 3 - Esquema de um armazenamento de energia térmica através do uso da energia solar [5]

Isto é, por exemplo, de uma forma geral a tecnologia de armazenamento flywheels, armazena energia utilizando um aceleramento no rotor (flywheel) atingindo velocidades muito altas, o que permite conservar energia no sistema como energia rotacional. Em suma, quando a flywheel está descarregar energia o motor inverte o seu campo, passando a funcionar como gerador. Nesta situação a velocidade de rotação do flywheel do motor é reduzida por consequência do princípio da conservação da energia, em situações de carregamento de energia existe um aumento na velocidade do flywheel.

Portanto, neste sistema a primeira fase de controlo, corresponde, por exemplo, aos sinais que devem ser enviados ao equipamento para ser ativado e assim, mudar o funcionamento de gerador para motor, permitindo a passagem de fluxo de energia para o motor, de modo a acelerar o flywheel do mesmo (fase de armazenamento de energia).

Da mesma forma deve-se controlar o ciclo de descarga. Isto é, esta fase, não é nada mais do que efetuar um diagnóstico do sistema e dar "ordens" de modo a que o sistema possa funcionar corretamente, sendo também responsável pela ativação das proteções, em caso de necessidade.
A segunda fase de controlo consiste em determinar fatores como definição do preço a que deve ser vendida a energia, verificação da quantidade de energia necessária a descarregar para a rede, de modo a satisfazer a procura num determinado momento, entre outros fatores.

\section{Vantagens Técnicas e Económicas dos ESS's}

A implementação dos ESS's acarretam diversas vantagens, nomeadamente, técnicas e económicas, que serão descritas de seguida.

\subsection{Vantagens Técnicas}

Como já foi referido no ponto 1 , os ESS's conduzem a vantagens relacionadas com a possibilidade de diminuir o desperdício da energia.

Atualmente, existem dois modos de produção de energia para o qual o armazenamento é claramente importante:

- Produção de energia convencional:

Neste caso o armazenamento de energia poderá compensar uma perda temporária da produção de uma das unidades geradoras. 
Visto que, existe uma obrigação contratual com a demanda por parte das concessionárias, se ocorrer alguma falha de abastecimento de eletricidade, estas poderão de incorrer de penalidades, tais como, multas avultadas. Com a possibilidade de armazenar a energia esta situação pode ser precavida.

Portanto, o nível de energia é comparável ao estipulado e a quantidade de energia armazenada deve ser um compromisso entre a duração desejável da reserva de energia e as possíveis penalidades [3].

- Produção de energia renovável:

Em relação a este tipo de produção, o armazenamento tem o intuito de armazenar em horas em que a procura é baixa e utilizar esta energia durante o período de horas de pico. O objetivo desta situação é, uma vez mais, garantir o compromisso contratual. No entanto, nesta situação o custo de armazenamento deve ser considerado. Além disso, a energia armazenada somente poderá satisfazer uma parte da capacidade nominal de produção [3].

\subsection{Vantagens Económicas}

Atualmente, e cada vez mais, existe um grande número de consumidores com necessidades de energia de grande alcance.
O consumo diário dos utilizadores caracteriza-se pela forte instabilidade, isto é, ao longo das 24 horas do dia, o consumo diário não é constante, como se pode observar na Figura 4. Nesta verifica-se que a energia necessária para satisfazer o consumo nas horas de pico é, praticamente, o dobro do valor necessário para satisfazer a procura nas horas de menor consumo [6].

Sabendo que o dimensionamento dos componentes da rede elétrica correspondem ao momento de maior procura, constata-se que na grande maioria do tempo esses componentes encontram-se sobredimensionados. Portanto, existe a possibilidade de nivelar a energia produzida considerando o valor médio da procura ao longo do dia ao invés do que é efetuado atualmente. Pode-se, então, produzir energia a um nível mais reduzido do que o valor de pico, permitindo a diminuição do dimensionamento dos componentes da rede. Assim, ter-se-ia uma situação de produção praticamente constante, onde a introdução dos ESS's na rede elétrica era necessária. Ou seja, apesar de constante o valor produzido, a energia total produzida teria de satisfazer de igual modo a demanda, cujos ESS's teriam a função de armazenar a energia quando era em excesso e entregá-la à rede quando existisse falta dela.

Esta situação permitiria poupar nos gastos obtidos com o sobredimensionamento dos componentes da rede elétrica, contudo, para esta situação ser viável as tecnologias de armazenamento de energia elétrica teriam de estar num patamar mais evoluído [3].

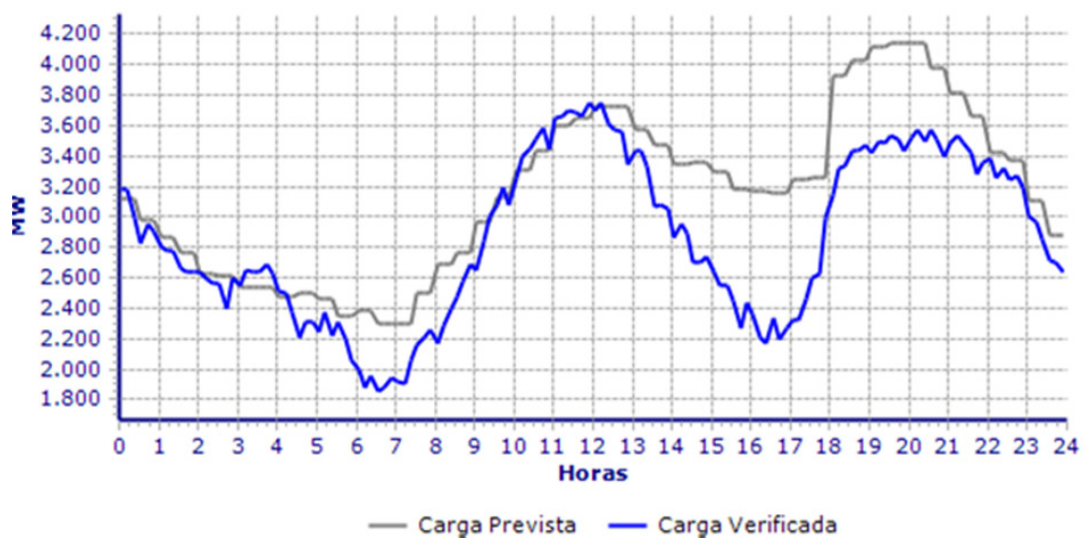

Figura 4 - Diagrama de cargas verificados no dia 04/11/2012 [6] 


\section{Comparação entre as Tecnologias de Armazenamento de Energia}

Presentemente existem diversas tecnologias para 0 armazenamento de energia elétrica, que podem ser agrupadas conforme a Figura 5. Como se pode verificar, e anteriormente já referido, pode-se dividir as tecnologias em 5 grandes categorias, nomeadamente [7]:

- elétrica;

- eletroquímica;

- química;

- mecânica;

- térmica.

As tecnologias de armazenamento de energia podem ser classificadas consoante a sua capacidade [8]:

- Grande escala (GW):

Armazenamento térmico, armazenamento de energia por bombeamento de água (pumped hydro energy storage - PHES), armazenamento de energia por ar comprimido (compressed air energy storage - CAES), armazenamento químico (por exemplo, hidrogénio em larga escala> 100MW, até semanas e meses);
- Potência:

supercondensadores, armazenamento de energia por supercondutores magnéticos (superconducting magnetic energy storage - SMES), flywheels;

- Energia:

Baterias, tais como, chumbo ácido (lead-acid - LA), iões de lítio (Li-ion), baterias de fluxo e NaS (enxofre de sódio);

- Energia e potência:

baterias de LA e Li-ion;

- Armazenamento de energia de hidrogénio, CAES, PHES. (pequena escala, $10 \mathrm{MW}<\mathrm{P}>100 \mathrm{MW}$, horas ou dias).

- Micro escala (kW):

- Potência: supercondensadores, flywheels;

- Energia: baterias, tais como, chumbo ácido e Li-ion;

- Energia e Potência: baterias de Li-ion.

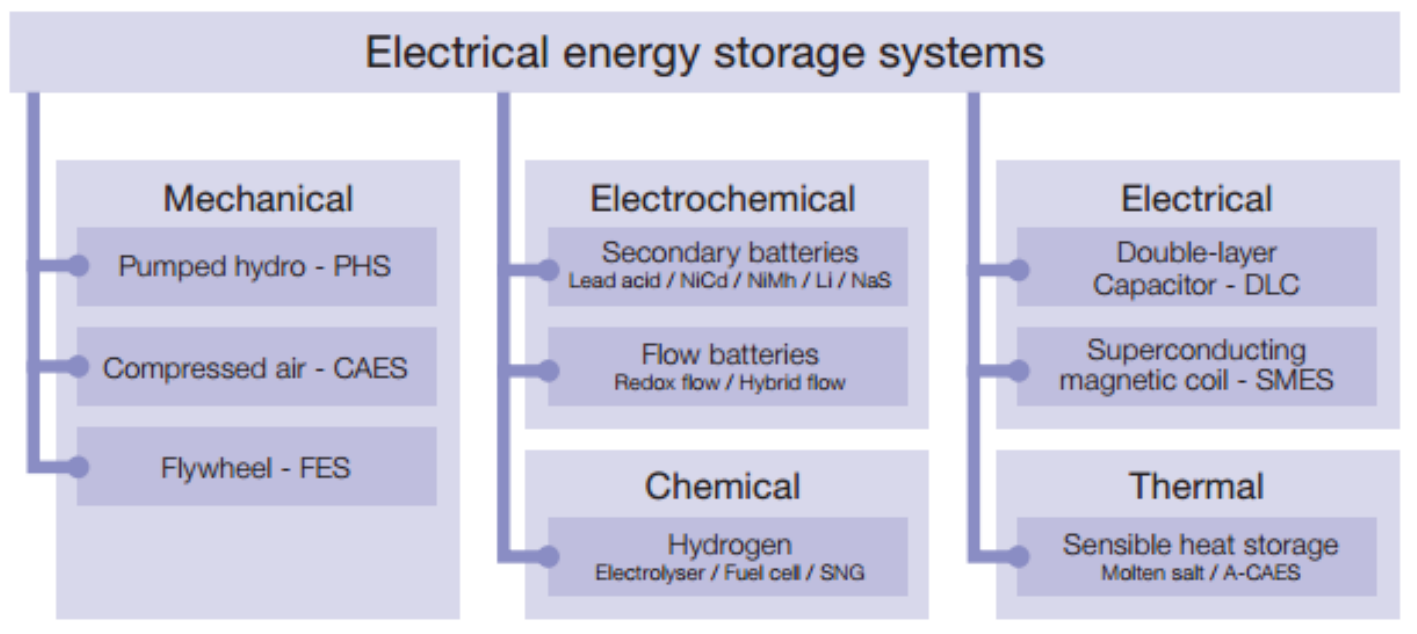

Figura 5 - Tecnologias de armazenamento de energia elétrica [7] 


\subsection{Unidades de Armazenamento Elétricas}

Dentro das unidades de armazenamento com características elétricas tem-se: camada dupla de condensadores (doublelayer capacitors - DLC) e armazenamento de energia por supercondutores magnéticos (superconducting magnetic energy storage-SMES).

\section{Camada dupla de condensadores (DLC):}

Esta tecnologia é também conhecida por supercondensadores [7], sendo os mais recentes dispositivos inovadores na área de armazenamento de energia elétrica. Pois, em comparação com a bateria ou o condensador tradicional, o supercondensador possui uma estabilidade no ciclo quase ilimitada, bem como uma capacidade de potência extremamente elevada, uma baixa densidade de energia e custos de investimento elevados [9].

As duas principais características são os valores extremamente altos da sua capacitância, da ordem de muitos milhares de faradays, para além da possibilidade de carga e descarga muito rápido devido à baixa resistência interna, recursos que as baterias convencionais não possuem [7].

Geralmente, os supercondensadores usufruem uma vida útil entre 8-10 anos, tendo uma eficiência de 95\%. São bastantes confiáveis, sem manutenção e podem trabalhar em diversos ambientes e temperaturas. Estas unidades são "amigas" do ambiente e facilmente podem ser recicladas ou neutralizadas [3] [7].

Tal como sistemas de baterias, os condensadores podem trabalhar em corrente contínua. Este facto impõe a utilização de sistemas eletrónicos de potência, tal como é apresentado na Figura 6.

Ao longo dos últimos anos têm vindo a ser aplicados em produtos eletrónicos, usados como UPS's em caso de falha momentânea de tensão e aplicados em veículos elétricos, onde podem ser utilizados nos processos de aceleração e travagem regenerativa [7].
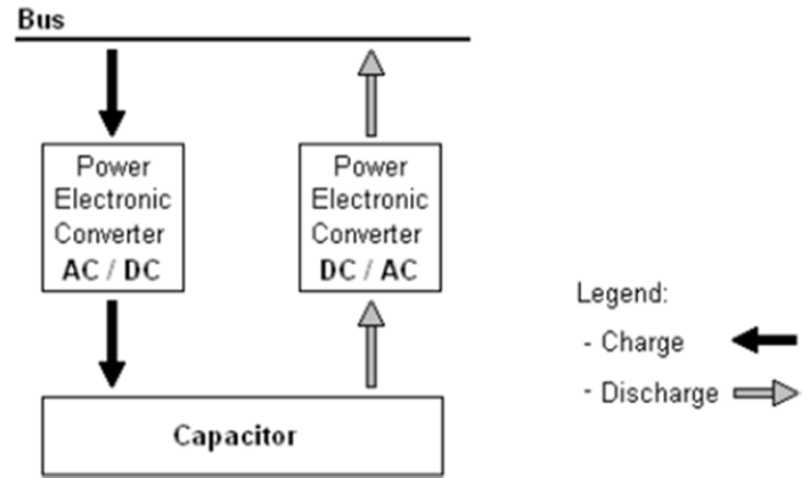

Figura 6 - Diagrama de operação de um dispositivo supercondensador [9]

Supercondutores magnéticos (SMES):

Os SMES funciona de acordo com o princípio da eletrodinâmica. Isto é, armazena energia sob a forma de um campo magnético que é criado através de um fluxo de corrente contínua por uma bobina supercondutora. Para armazenar energia proveniente de um barramento de energia, precedentemente a corrente alternada deve ser convertida em corrente contínua e, assim, possa ser injetada na bobina. O processo contrário também é aplicável, sendo que a corrente contínua armazenada tem de ser convertida em alternada, de modo a ser possível injetá-la na rede elétrica. Para tal, entre o barramento e a bobina terá de haver conversores eletrónicos de potência. O diagrama de operação do dispositivo SMES é apresentado na Figura 7 [9].

Bus

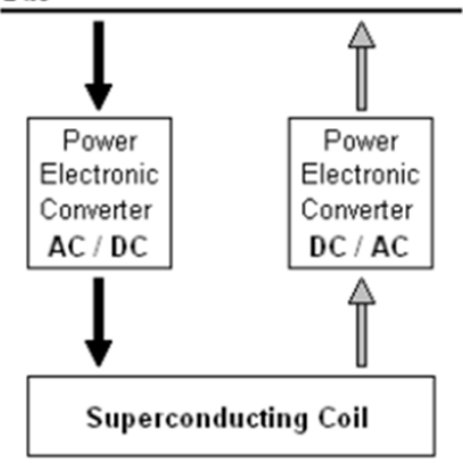

Legend:

- Charge

- Discharge $\Longrightarrow$

Figura 7 - Diagrama de operação de um dispositivo SMES [9] 
Portanto, o componente principal deste sistema de armazenamento é feito de uma bobina de material supercondutor, sendo que os restantes componentes incluem equipamentos de condicionamento de energia e um sistema de refrigeração criogênica resfriada [7].

A principal vantagem dos SMES é o tempo de resposta, ou seja, se uma determinada potência é requerida, esta fica disponível quase instantaneamente. Além disso, o sistema é caracterizado pela sua elevada eficiência, perto de 95\% para um ciclo de carga e descarga [3]. Contudo, a confiabilidade global depende crucialmente do sistema de refrigeração [7].

Além disso, estes sistemas são capazes de descarregar quase a totalidade da energia armazenada, ao contrário das baterias. Estas unidades de armazenamento são muito úteis para aplicações que requerem operação contínua com um grande número de ciclos completos carga-descarga. O tempo de resposta rápido (inferior a 100ms) destes sistemas tornaos ideais para regular a estabilidade da rede (nivelamento de carga). A sua principal desvantagem é o sistema de refrigeração que é muito caro e faz operações mais complexas.

\subsection{Unidades de Armazenamento Eletroquímicas}

As baterias armazenam energia sob a forma eletroquímica através da criação de iões eletricamente carregados. Isto é, quando a bateria está a carregar a corrente contínua é convertida em energia química, quando a bateria descarrega, a energia é novamente convertida num fluxo de eletrões sob a forma de corrente contínua [9].

A Figura 8 apresenta a operação entre uma bateria e a rede elétrica de energia.

Deste modo, a utilização de baterias implicam o uso de conversores eletrónicos de potência, a fim de converter a corrente alternada em corrente contínua nos períodos de carregamento e, vice-versa, no processo de descarga. [9]

A tecnologia das baterias está subdividida em dois conceitos: baterias secundárias e baterias de fluxo (Figura 5) [7].
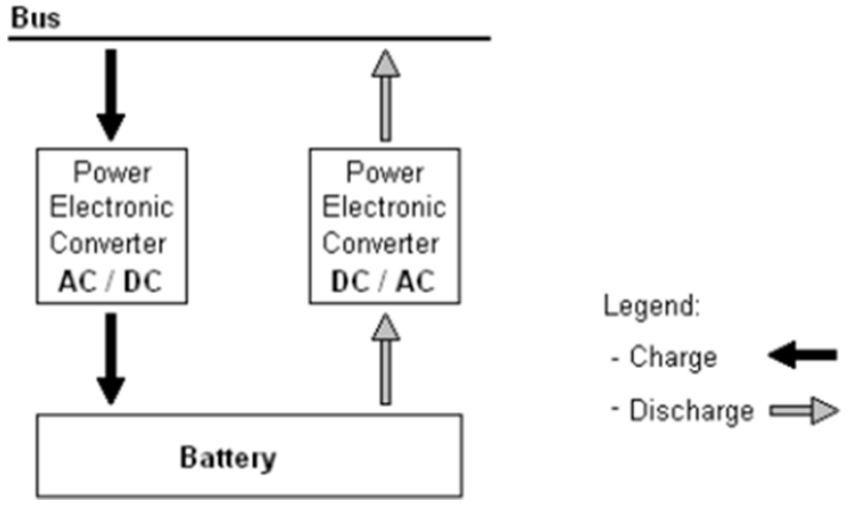

Figura 8 - Diagrama de operação de uma bateria [9]

As baterias secundárias usam elétrodos para ambas as situações, tanto para o processo de transferência de eletrões como para armazenar os produtos ou reagentes provenientes das reações em estado sólido do elétrodo [9].

Deste grupo fazem parte as baterias: chumbo-ácido (leadacid - LA), níquel-cádmio ( $\mathrm{NiCd}$ ), hidreto metálico de níquel (NiMH), iões lítio (Li-ion), enxofre de sódio ( $\mathrm{NaS}$ ),entre outras [7].

\section{Características gerais:}

- $\underline{\text { LA: }}$

São aplicadas em sistemas de alimentação de emergência, como base dos sistemas fotovoltaicos, sistemas de baterias para a mitigação das flutuações de energia eólica e como baterias de arranque de veículos.

Possuem uma vida útil típica entre 6 a 15 anos, normalmente com uma vida de 1500 ciclos. Com eficiência entre $80 \%$ a $90 \%$, tendo um custo relativamente baixo [7].

\section{- NiCd e NiMH:}

Atualmente, não são muito usadas devido ao perigo da toxidade do cádmio, sendo substituídas pelas $\mathrm{NiMH}$. Contudo, este tipo de baterias comparando com as LA, possuem um ligeiro aumento da densidade de energia e o número de ciclos é mais elevado [7]. 
As suas aplicações hoje em dia são muito importantes, para computadores portáteis, telemóveis, bicicletas elétricas, veículos elétricos, entre outras.

Possuem uma elevada densidade de energia e têm custos relativamente baixos devido à sua produção em massa. A sua eficiência ronda os $95 \%$ e os $98 \%$ [7].

- $\quad$ NaS:

Os ciclos de vida típicos é de cerca de 4500 ciclos e têm um tempo de descarga entre 6,0 horas para 7,2 horas. Tem uma eficiência cerca de $75 \%$ e permitem resposta rápida. A principal

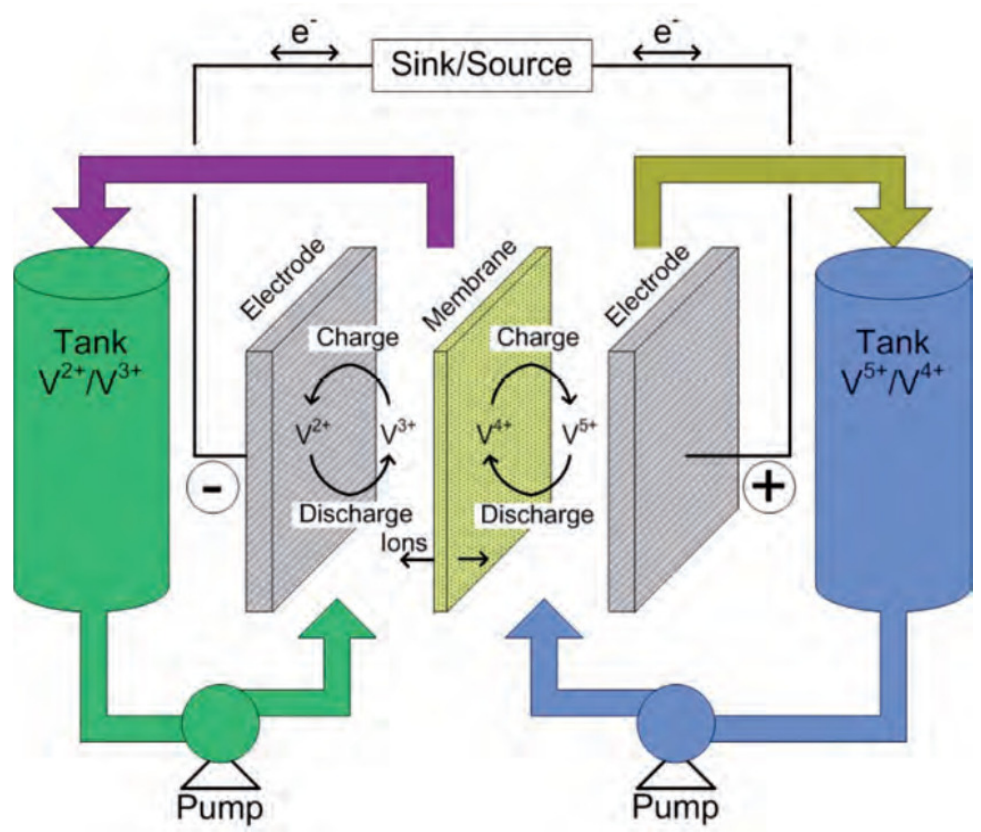

Figura 9 - Esquema de uma bateria de VRB [7] desvantagem é o facto que para manter a temperatura de operação é necessária uma fonte de calor, sendo que reduz parcialmente o desempenho da bateria [7].

Dentro das baterias de fluxo fazem parte as de fluxo redox e as de fluxo híbrido. As primeiras são dispositivos de armazenamento que convertem energia elétrica em energia potencial química através do uso de duas soluções de eletrólitos líquidos e, posteriormente, liberando a energia armazenada durante a descarga. Os dois eletrólitos são separados por uma membrana semipermeável. Esta membrana permite o fluxo de iões, mas impede a mistura dos líquidos. O contacto elétrico é feito através de condutores inertes nos líquidos. Como os iões fluem através da membrana, uma corrente elétrica é induzida nos condutores. [9]

Estes tipos são baterias redox de vanádio (VRB) (Figura 9), as baterias de brometo de polisulfureto (PSB) e do zinco bromo $(\mathrm{ZnBr})[9]$.

Nas baterias de fluxo híbrido uma das massas ativas é armazenada internamente no interior da célula eletroquímica, enquanto o outro permanece no

eletrólito líquido, que são armazenadas externamente num reservatório. Portanto, as células de fluxo híbrido combinam características de baterias secundárias convencionais e baterias de fluxo redox. A capacidade da bateria depende do tamanho da célula eletroquímica [7]. Exemplo típico é o sistema de $\mathrm{ZnBr}$ híbridos [9].

\subsection{Unidades de Armazenamento Químicas}

Algumas das tecnologias presentes nesta categoria são as células de combustível de hidrogénio e o gás natural sintético (synthetic natural gas - SNG) [3] [7].

O principal objetivo do sistema de armazenamento de energia química é usar o "excesso" de energia elétrica para a produção de hidrogénio via eletrólise da água. Neste caso é possível usar o hidrogénio como um portador de energia, seja como hidrogénio puro ou como SNG [7].

Embora a eficiência global do hidrogénio e do SNG seja baixa quando comparado a outras tecnologias de armazenamento, como PHS e Li-ion, o armazenamento de energia química é a única que permite 0 armazenamento de grandes quantidades de energia, até à faixa TWh, e por maiores períodos de tempo [7]. 
Esta tecnologia também pode ser aplicada a sectores, como o transporte, aquecimento e a indústria química.

\section{Células de combustível de hidrogénio:}

O sistema de armazenamento de hidrogénio consiste em três componentes principais: eletrólise, que consome eletricidade nas horas de menor consumo para produzir hidrogénio; a célula de combustível, que utiliza o hidrogénio e o oxigénio do ar para gerar eletricidade; e um reservatório de hidrogénio para garantir os recursos adequados quando são necessários [3].

Existem muitos tipos de células de combustível, sendo a mais conhecida a pilha alcalina de combustível entre as demais.

As diferenças básicas entre estes tipos de baterias são os eletrólitos utilizados, temperatura de funcionamento, o design e o seu campo de aplicação. Além disso, cada tipo tem necessidades de combustível específico [3] [7].

Esta tecnologia pode ser usada na produção descentralizada (particularmente de baixas potências, de emergências, entre outras), fornecimento espontâneo relacionado ou não à rede, potência média [3].

\subsection{Unidades de Armazenamento Mecânicas}

Existem três tipos de tecnologias dentro desta categoria:

Armazenamento de energia pelo bombeamento de água (pumped-hydro-PH):

Esta tecnologia utiliza a energia com origem numa fonte renovável nas horas de pouco consumo, para bombear a água de uma albufeira a jusante de uma barragem para uma albufeira a montante. Assim, a PH permite que a água possa ser mais do que uma vez turbinada, e como a água é um recurso que é gratuito, esta situação só trás vantagens ao setor de produção elétrica, como se pode comprovar pela Figura 10. Atualmente é mais utilizada para aplicações de alta potência (algumas dezenas de GWh ou 100 de MW).
A principal desvantagem desta tecnologia é a necessidade de um sítio com diferentes elevações para poder bombear a água e, esta possa ser utilizada num sistema hidroelétrico para produzir eletricidade [3] [7] $[9]$.
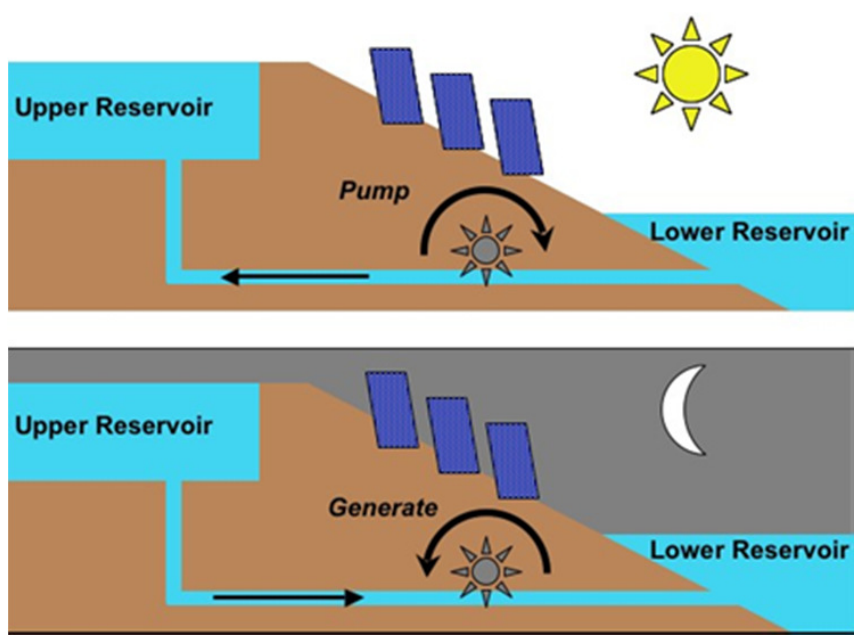

Figura 10 - Exemplo de um sistema de bombagem [10]

\section{Flywheel:}

Esta tecnologia utiliza dois tipos de acumuladores de energia, ou são constituídas por um flywheel (volante) maciço ou composto, para além de um motor/gerador e suportes especiais (muitas vezes magnéticos). Uma das características das flywheels é a capacidade de fazer inúmeros ciclos (entre 10.000 e 100.000 ciclos) [3] [7].

Este sistema permite armazenar energia elétrica sob a forma de energia cinética, daí os flywheels terem elevados requisitos, de modo a poderem atingir elevadas velocidades [7].

O armazenamento de energia cinética pode ser usado na distribuição de eletricidade em meios urbanos através de baterias de grande capacidade, comparáveis aos reservatórios de água, com o objetivo de maximizar a eficiência das unidades de produção. Por exemplo, em grandes instalações com cerca de 40 unidades (25kW$25 \mathrm{kWh}$ ), estes são capazes de armazenar $1 \mathrm{MW}$ que pode ser libertado em menos de 1 hora [3]. 
Armazenamento de energia a ar comprimido (CAES):

É um dispositivo com base numa turbina a gás, onde os processos de compressão e combustão estão divididos. Durante a carga, o compressor é acoplado à máquina elétrica, que trabalha como motor, comprimindo o ar. Após a compressão, o ar é armazenado em cavernas subterrâneas seladas. A descarga do dispositivo consiste em gerar energia através do acoplamento de uma turbina a gás com uma máquina elétrica, funcionando como gerador, e fornecendo o ar comprimido armazenado para o processo de combustão [3] [9].

Um diagrama de operação de um sistema de armazenamento de energia a ar comprimido é apresentado na Figura 11 [9].

O ar pode ser comprimido e armazenado no subsolo, com tubagem de alta pressão (20-100 bar).

A densidade de energia neste tipo de sistemas é na ordem de $12 \mathrm{kWh} / \mathrm{m} 3$, enquanto a eficiência estimada é de cerca de $70 \%[3]$.

\subsection{Unidades de Armazenamento Térmicas}

Existem dois tipos de sistemas de armazenamento térmico, dependendo se eles usam o calor sensível ou latente. As transferências de calor entre o acumulador térmico e o ambiente exterior são feitas através de um fluido de transferência de calor, isto é tem de haver diferença de temperaturas [3].
O armazenamento de calor latente corresponde há mudança do estado sólido para o líquido. Este tipo de armazenamento tem como vantagem armazenar grandes quantidades de energia num pequeno volume, o que permite uma maior eficiência na transferência de calor [7].

O armazenamento térmico de calor sensível é conseguido pelo aquecimento de um material em massa (sódio, sal fundido, água pressurizada, etc.) que não muda de estado durante a fase de acumulação. Assim, o calor é recuperado para produzir vapor de água, que conduz a um sistema de turboalternador [3].

Os sistemas de armazenamento térmico são implantados para superar o descompasso entre a procura e a oferta de energia térmica e, portanto, são importantes para a integração de fontes de energias renováveis [7].

\section{Considerações gerais}

Como se verificou existem diversas tecnologias de armazenamento de energia, que também podem ser classificadas consoante o tempo de descarga de energia, como se pode observar na Figura 12.

Portanto, esta classificação divide-se em: curto e longo prazo de capacidade de descarga de energia. No primeiro grupo destacam-se as flywheels, supercondensadores e os supercondutores magnéticos. A longo prazo destacam-se as tecnologias de armazenamento de energia por bombeamento de água (pumped hydro), por ar comprimido, por baterias e por células de combustível de hidrogénio [9].

Bus

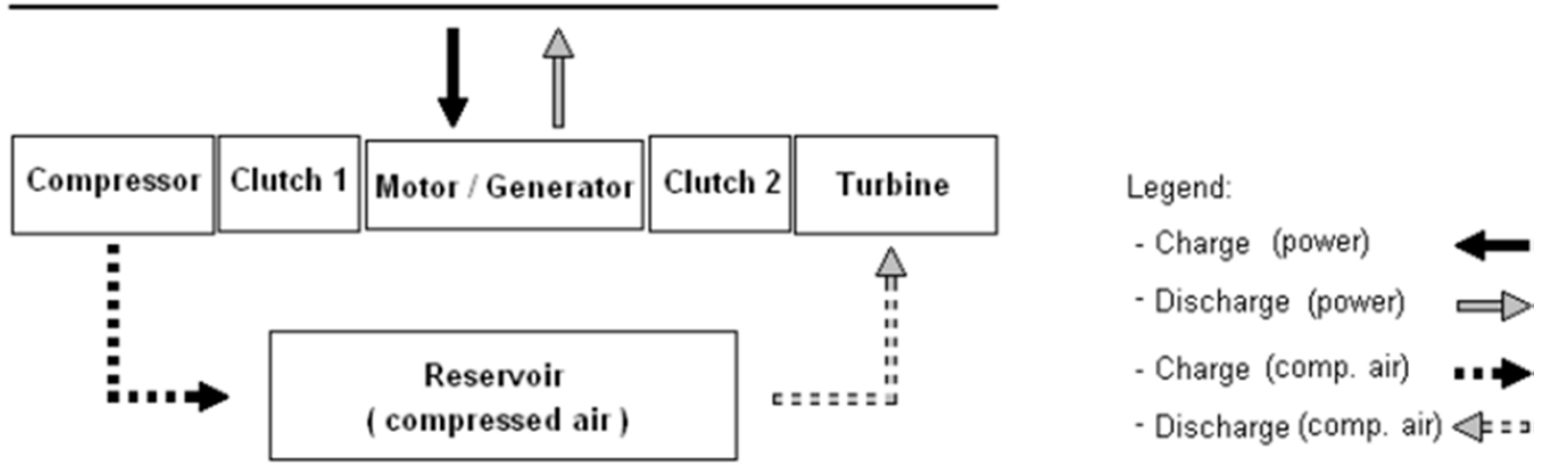

Figura 11 - Diagrama de operação de um armazenamento por compressão do ar [9] 


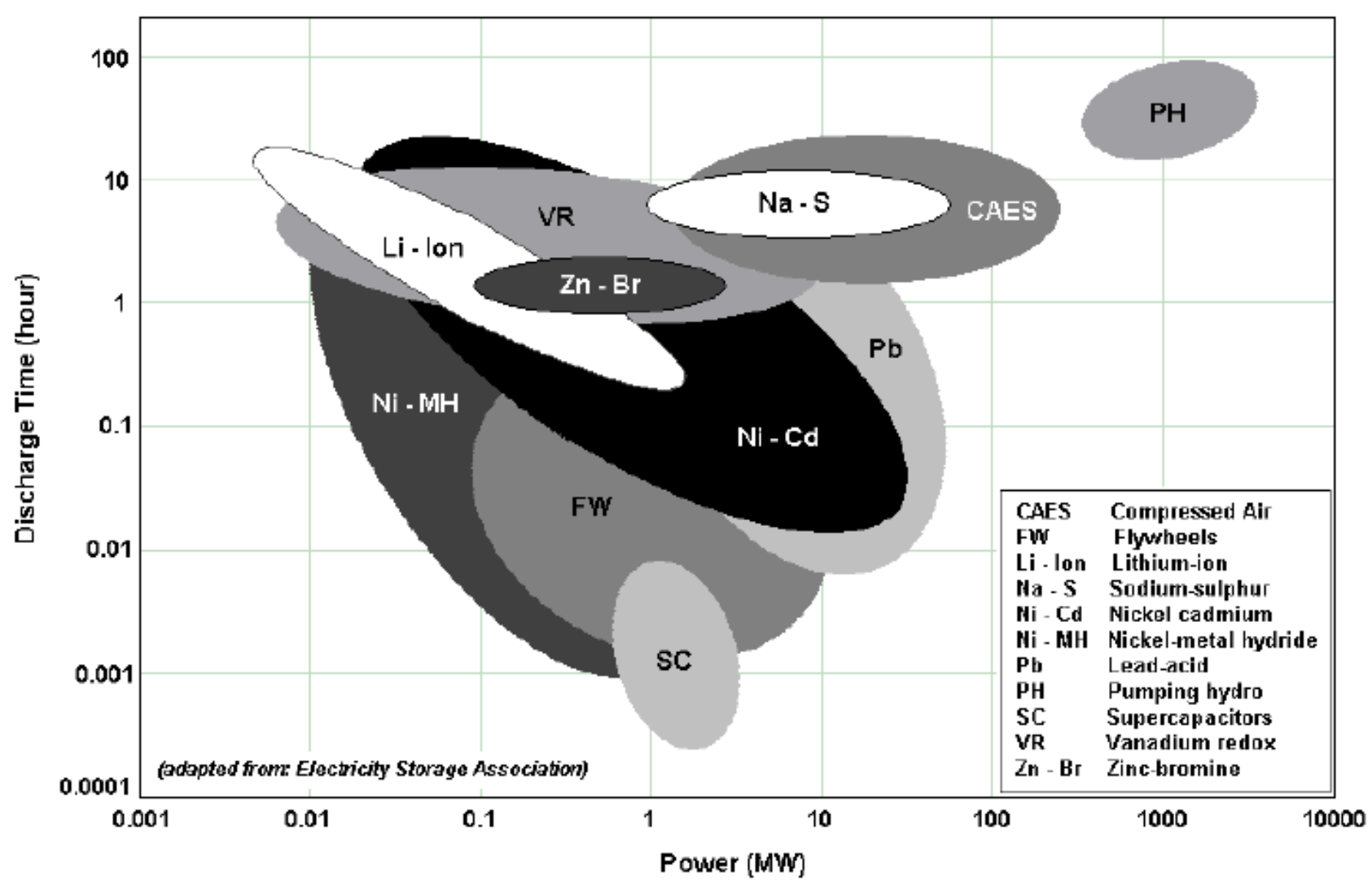

Figura 12 - Comparação entre as diversas tecnologias de armazenamento tendo em conta o tempo de descarga e a potência [9]

Posto isto, é de salientar que as diversas técnicas de armazenamento de energia disponíveis podem ser aplicadas a sistemas de energia elétrica.

Sendo que, estas acarretam custos associados ao armazenamento de energia, mas podem ser soluções rentáveis. Pois, permitem gerir a rede, garantindo o nivelamento da carga em tempo real, bem como uma melhor utilização de recursos renováveis evitando o corte de carga em tempos de menor produção [3].

Contudo, ainda existe a necessidade de melhorar as técnicas de armazenamento, de modo a que estas possam ser cada vez mais úteis e aplicadas no setor de energia elétrica.

\section{Referências}

[1] APREN, "Evolução da produção de eletricidade em Portugal entre 1999 e 2012 (c/correção de hidraulicidade)", 2013.

(http://www.apren.pt/dadostecnicos/index.php?id=272 \&cat=266)

[2] Rudell A. "Storage and Fuel Cells. EPSRC SuperGen Workshop: Future Technologies for a Sustainable Electricity System". University of Cambridge; 2003.

[3] H. Ibrahim, A. Ilinca, J. Perron, "Energy storage systemsCharacteristics and comparisons, Renewable and Sustainable Energy Reviews", Volume 12, Issue 5, June 2008, Pages 1221-1250, ISSN 1364-0321. 
[4] Quanta-technology, "Electric Energy Storage Systems", 2013.

(http://www.quanta-

technology.com/sites/default/files/doc-

files/Energy_Storage-12-01-13.pdf)

[5] Volker.quasching, "Solar thermal power plants", 2013.

(http://www.volker-

quaschning.de/articles/fundamentals2/index.php)

[6] REN, "Diagrama de Carga da RNT", 2012.

(http://www.centrodeinformacao.ren.pt/PT/Informacao Exploracao/Paginas/DiagramadeCargadaRNT.aspx)

[7] IEC, "Electric Energy Storage", 2011.

(http://www.iec.ch/whitepaper/pdf/iecWP-

energystorage-LR-en.pdf)
[8] Comissão Europeia, "The future role and challenges of Energy Storage", DG ENER Working Paper, 2013.

(http://ec.europa.eu/energy/infrastructure/doc/energystorage/2013/energy_storage.pdf)

[9] Sergio Faias, Jorge Sousa and Rui Castro (2009). "Embedded Energy Storage Systems in the Power Grid for Renewable Energy Sources Integration, Renewable Energy, T J Hammons (Ed.), ISBN: 978-953-7619-52-7, InTech.

(http://www.intechopen.com/books/renewableenergy/embedded-energy-storagesystems-in-the-powergrid-for-renewable-energy-sources-integration)

[10]Creighton, "Storing energy", 2013.

(http://www.creighton.edu/green/energytutorials/forms ofenergy/storingenergy/index.php)

\begin{tabular}{lllll}
\hline \multirow{2}{*}{ Divulgação: } & Título: & Instalações Elétricas de Baixa Tensão & ISBN: & 9789897230264 \\
& Autor: & António Augusto Araújo Gomes & No Páginas: & 150 \\
& Editora: & Publindústria & Encadernação: & Capa mole \\
& Data: & Fevereiro 2013 & &
\end{tabular}
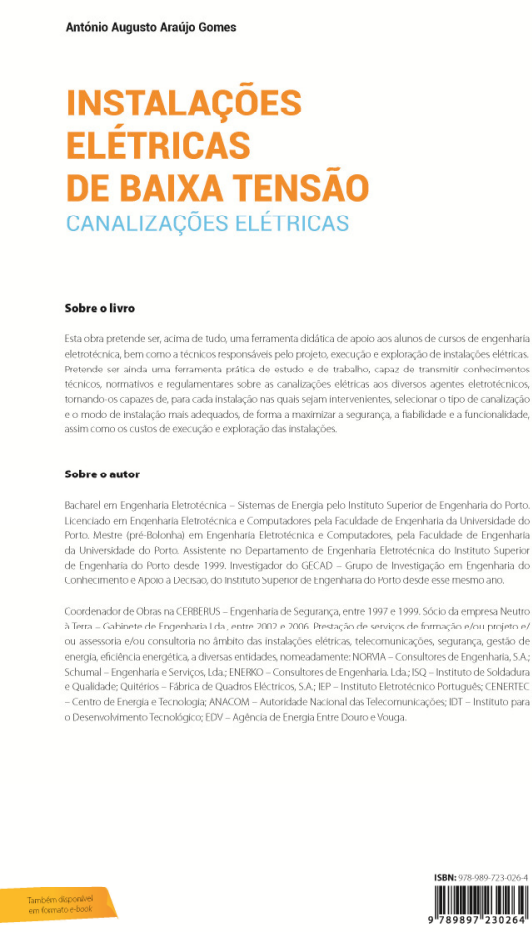

wuw. engedook. com
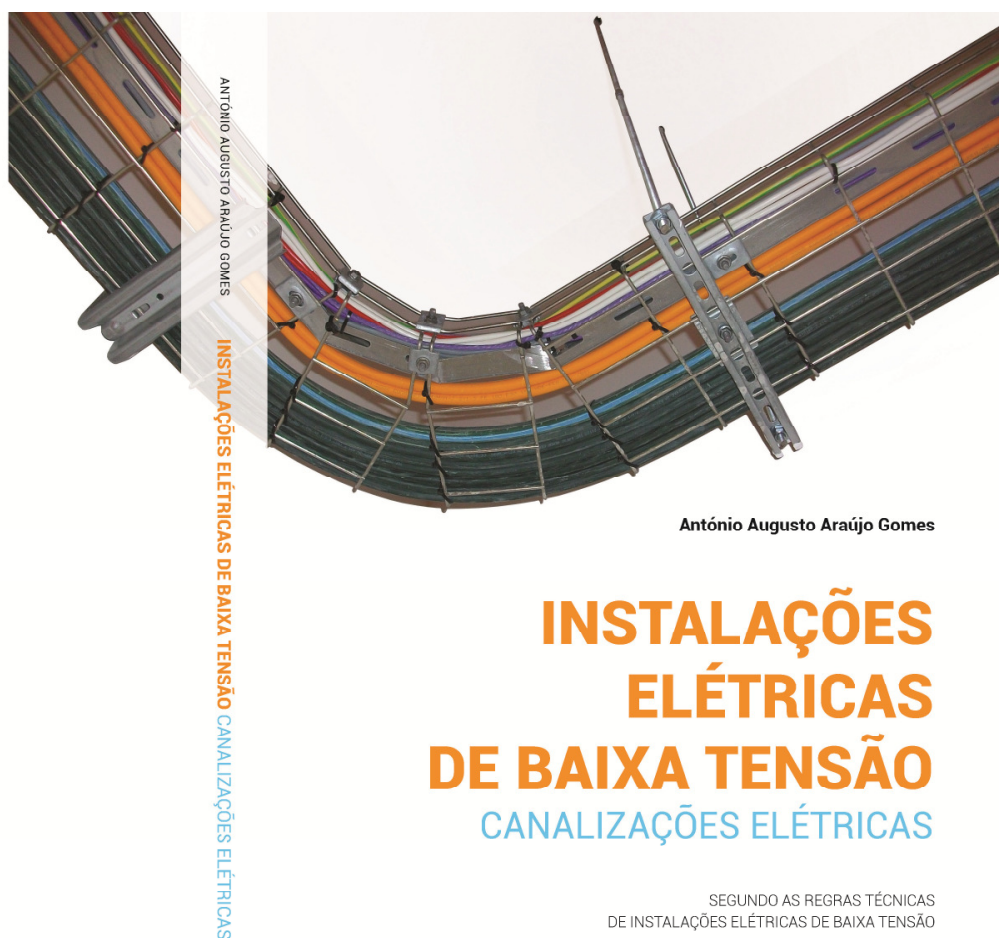